\title{
A journey that motivates: Exploring the Associate Students Transition Framework
}

\author{
line 1: $1^{\text {st }}$ Given Name Surname \\ line 2: dept. name of organization \\ (of Affiliation) \\ line 3: name of organization \\ (of Affiliation) \\ line 4: City, Country
}

line 5: email address or ORCID

\author{
line 1: $4^{\text {th }}$ Given Name Surname \\ line 2: dept. name of organization \\ (of Affiliation) \\ line 3: name of organization \\ (of Affiliation) \\ line 4: City, Country
}

line 5: email address or ORCID

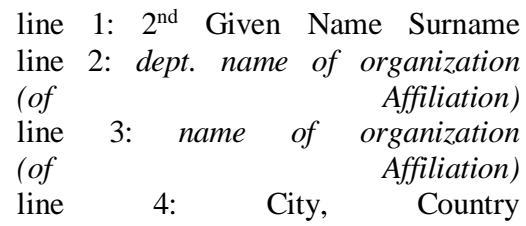

line 5: email address or ORCID

\begin{abstract}
This research to practice full paper presents empirical work exploring the transition experiences of transfer students into computing degrees in Scotland. Students on this journey face transitional barriers as they adapt to the change in culture, come to terms with their altered student identity, and overcome academic and social integration issues. The study discussed employed the graphical research method of photoelicitation to gather and document perceptions of thirteen students during the first stage of their higher education journey, as they prepare to make the transition from community college into a university. A further ten participants shared their experience of transition during the first few weeks at university through photovoice and in-depth IPA interviews, providing insight into the usually unseen aspects of transition, moving home, adjusting to a long commute, experiencing loneliness and anxiety, benefiting from peer support and friendship. Through graphical research methods and interpretative phenomenological analysis, the participants have shaped the research through their narrative, their photographs, and their discussion to form a representation of the phenomenon under examination.
\end{abstract}

Findings are shared which identified this as a "journey that motivated", one that made "university possible" and one that combined two "different worlds". This study found that the students' perceptions and experiences of transition were diverse and highlight the need to understand the key aspects of adjustment. This paper explores a theoretical framework adapted from the Model of Organizational influence on the development of Learner Identity [1], that can be applied across institutions for all students in transition. Grounded in the literature the framework demonstrates the student perspectives before the transition and, experience after the transition. This framework provides a mechanism for improving the transition for computing and engineering students moving into university study and makes a valuable contribution to computing education.

Keywords - transfer students, higher education, preparation, qualitative, phenomenology, photo elicitation

\section{INTRODUCTION}

"Transition is often depicted as a problematic phase that must be smoothed, bridged and made successful, with the help of staff and institutional initiatives" [2]. Students who join university as transfer students in computing and engineering often struggle to fit in and experience a lengthy period of adjustment which can see them face challenges both academically and socially. These individuals can feel less worthy, less able, and often initially, do not identify as university students. Coming from community college can have a stigma, a lower status. Sometimes these students do not meet the standard first year entry requirements for university study, or they may be the first in their family to follow this path. Their transition can be difficult.

Nonetheless, within Scotland, students that transition from community college courses into a university degree programme are following a route known to be fundamental in supporting disadvantaged learners to progress to degree study [3]. The Scottish Funding Council (SFC) believe that the development of articulation pathways provides a clear widening access route and have set ambitious targets for Scottish universities to increase this provision. Students taking this route are faced with additional challenges and are more likely to drop out of their studies [4]. This paper explores computing students on this journey from community college to university education who experience transition as associate students, a term and identity which is worthy of further exploration due to the limited research with this group of students. Using interpretative and graphical methods this paper will allow the students following this route to share their experience not only through words but also through photographs.

This research focuses on associate students, an identity and additional route from community college into the university which was developed through additional funding in 2013. The background of this development is explored in Context section. Most researchers in the field agree that identity is socially constructed and formed of our self-belief, our interactions and the social groups we inhabit, which in turn, influence our norms, expectations and beliefs [5]. Student identity has formed through school experiences and for the students in this study, also formed through the impact of their community college time. Listening to the student voice involves exploring their lived experiences of adjustment, hearing their expectations and perceptions.

There is now a considerable body of research which suggests that educational transitions are recognised as multiple, multi-dimensional and individual [6][7][8][9] providing universities with a difficult challenge in determining appropriate methods of support. Listening to the student's voice offers insight for institutions and provides an opportunity for students to shape the support mechanisms on offer. This study recommends a framework for supporting students in transition. The Model of Organisational influence on the development of Learner Identity [1], is highly regarded and focuses on the development of learner identity which is underpinned by Tinto's principles which recommend developing a 
supportive culture for learner development. This study draws upon the first section of the model, exploring imagining, aspiration, expectations and skills and knowledge. The process of adjustment and how students themselves experience this during transition is fundamental to this study. The model is discussed fully in the Conceptual Framework chapter.

Exploring the experience of computing and engineering transfer students is of interest to other universities who support students and more widely within higher education as we explore the student voice. This study examines the perceptions and experience of the students and adds to the body of work around educational transitions.

Ethical approval for this research has been granted from the Edinburgh Napier Faculty Research Integrity Committee. At all times ethical considerations and the privacy of all participants has been prioritised, obtaining informed consent from individuals and anonymising contributions from all students. Throughout this paper, participants are identified by $\mathrm{P}$ [unique number]. The number of participants is higher due to some individuals taking part in the initial photographic stage but not completing the discussion element.

The paper begins by discussing educational transitions in the context of widening participation. The paper describes the Associate Student Transition Model as mechanism for institutions to support transfer students.

\section{CONTEXT}

\section{A. Widening Participation}

Widening Participation can be defined as the interventions and mechanisms put in place by institutions to encourage and support individuals from all backgrounds, in particular, those who have had limited exposure to higher education and those who have been "discouraged by social, cultural, economic or institutional barriers" to enter the higher education environment [10].

Since 2012, the Scottish Funding Council (SFC) followed an outcomes-based approach to funding and worked alongside community colleges and universities to agree targets and priorities in return for their funding from the Scottish Government. Through these Outcome Agreements (OA), colleges and universities are expected to grow their provision for students from the most deprived communities [11]. Despite this emphasis, the SFC's Triennial Review on Widening Access states that "universities have an under-representation from the most deprived communities in Scottish universities" [12]. This denotes the continued requirement to chase the ambition set out by the First Minister in 2014 - that $20 \%$ of new entrants to $\mathrm{HE}$ in 2030 should come from the $20 \%$ most deprived areas in Scotland. Community colleges play a key role in widening participation with 47 per cent of students who continue their studies at university making up 90 per cent of university students from disadvantaged backgrounds.

\section{B. Transitions}

The process or journey of transition can start before the physical change in campus or school location, with the introduction of preparation and pre-transition activities. Students arrive at university from many different pathways, having experienced different educational institutions and with varying perceptions of university and higher education. Research by [13] found that the differences students experienced between their college and university harmed their confidence, causing uncertainty and lowering their sense of belonging. These transitions are, therefore, not linear but complex and chaotic [14][15]. Transition to higher education is frequently cited as causing increased levels of anxiety and stress in students [16][17][18][19][20].

Before transition, students are often encouraged to prepare, and educational establishments at the next level frequently put bridging or access programmes in place to help students cross the 'boundary'. These pre-entry support programmes are found to be a critical element for student participation and success, with authors such as [21] reporting that students are impacted by fear of failure and a lack of confidence which can be improved by preparation activities. Lack of preparation can cause students to under-achieve and subsequently drop-out of university [4]. Bridging programmes have been shown to address a range of barriers, 'providing participants with a clear and realistic pathway to admission'[3]. These programmes provide a means of familiarisation with campuses, tutors, classmates and teaching styles, increasing aspiration, and removing barriers. A study by the Higher Education Academy examined preentry interventions and emphasised the importance of interventions which nurture the formation of peer group support, both academically and socially [22].

\section{Conceptual Framework}

A conceptual framework is the system of concepts, assumptions, expectations, beliefs and theories that support and inform the research [23]. When following an interpretative study, it is important to acknowledge that it is impossible to be completely free from bias. Following a framework brings informed insight to the research by listening to the body of work surrounding the topic under study and can ensure the researcher has surfaced any biases and preconceptions she may have.

The Model of Organisational Influence on the Development of Learner Identity [1] drew on the work of several scholars and the authors believed that establishing a positive learning identity was essential for developing persistence and success as a university student. The studies identified twelve factors that enable the growth of student identity. The model considers organisational influences, and this study can draw on the first section of the model which explores the aspiration and expectations the student develops as they begin to consider a future which includes university study. The second stage, commitment, represents the application. In the third section, the student moves through five stages - adjustment, development, gaining confidence, gaining autonomy and achievement. Finally, the student identifies and achieves success. The influences of the university, their administrative process, the support offered, 
the teaching methods, and personal contact are all incorporated in the model through the boxes on either side.

For this study, it is perceived that associate students may have already achieved some of these factors by registering as associate students during their time in college. They are exposed to interventions which seek to inspire and prepare them for the transition. How the students perceive, adjust and experience transition is the focus of this study.

\section{Methodology}

The study incorporated three data collection methods, interpretative phenomenological analysis (IPA), photovoice and photo elicitation interviews (PEI) and each of these is now examined. Phenomenology is a philosophy that examines how individuals make sense of the world and using phenomenology for this study allows the researcher to gather a comprehensive account of the lived experience of students and to derive 'general or universal meaning' [24]. Phenomenology is a qualitative research design which focuses on the commonality of a lived experience within a particular group and has been used extensively in research from sociology, psychology, health sciences and education [25].

Photo-elicitation is 'based on the simple idea of inserting a photograph (or photographs) into a qualitative interview' [26] to elicit data. The photo-elicitation method uses photographs to generate verbal discussion [27] and can help keep the interview structured and stimulating [28]. This method enables the researcher to add depth and detail to the participants' accounts [29] and encourages discussion of more abstract and/or sensitive aspects [30].

Photovoice is a participatory photography methodology in which participants use a camera to generate data, directly involving them in the research process. The photographs are used to support critical reflection amongst the participants and provide the researcher with 'direct entry into their point of view'[31][32]. Within educational research, photovoice has been used as a research method in many studies (see $[33][34][35][36]$, however, it remains underused in the field of transition.

IPA interviews are underpinned and influenced by phenomenology, hermeneutics and idiography. In simple terms, IPA is a qualitative research method which examines how individuals make sense of their major life experiences, meaning-focused; it is committed to understanding firstperson experiences from a third-person position. As the participants are trying to make sense of their world, the researcher is trying to make sense of the participants trying to make sense of their world [37].

Employing these methods, the data collection took place over three distinct years starting with the pilot project during the academic year 2015/16 followed by two further phases in $2016 / 17$ and 2017/18. There were 23 participants in total, a number appropriate for the phenomenological nature of this study; six students took part in the IPA interviews over the three years, there were four photovoice participants over two years and 13 photo-elicitation participants composed of two focus groups.

\section{FINDINGS}

Findings have shown that before transition, whilst studying at community college students have demonstrated their understanding of transition and of the adjustment necessary. They have a realistic view of university study. For many, this route has provided them with access to future study which might not otherwise have been an option and they are motivated by the challenges that lie ahead. Moving as a cohort, and with friends, provides comfort and eases the 'pain-barrier' of adjustment. There is a realisation that college in itself is not preparation with the teaching environment described as 'spoon-feeding'. However, the associate students understand the skills necessary such as report writing and self-direction. They have an awareness of the campus and teaching changes they will experience and appear ready for the challenge.

There were many similarities drawn with existing literature, but it must be noted that much of the literature cited has used participants after transition. The level of understanding of the university environment and sense of motivation garnered from being part of the associate student

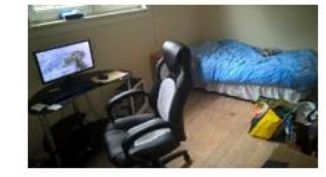

Figure 1: New beginnings: moving into a new home

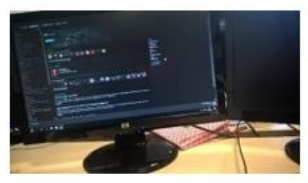

Figure 3: Becoming part of it: Joining a society

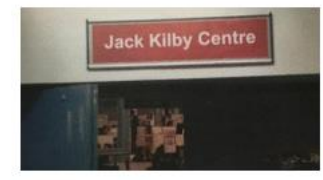

Figure 5: JKCC-if you're not here, you're not a computing student

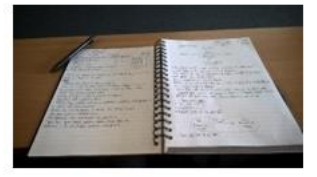

Figure 2: My new normal: regular day of noteakin

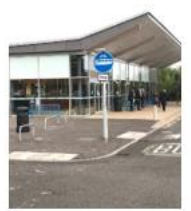

Figure 4: New beginning: start of my journey

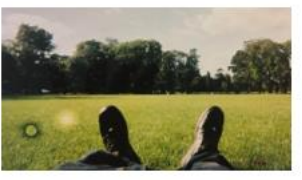

Figure 6: Chilling in the Meadows route is a recognised conclusion for this study in helping to understand the perceptions and experiences of associate students.

After transition into university, the stories and experiences shared by the student photovoice and IPA participants demonstrate their feelings of this change. The photographs chosen as most representative of the student community is shown in Figures 1 to 6.

The stories told exhibit a wide range of experience and give insight into the often-unseen details of this journey. Students were moving to a new house, adjusting to a new commute, experiencing loneliness and anxiety but also peer support and friendship. They struggled with the large campus and large class sizes but embraced the new social spaces, extended opening hours and opportunities to become a night-time student. They reflected on their journey to university and were grateful for the opportunity and additional benefits being an associate student had given them. 


\section{ASSOCIATE STUDENT TRANSITION FRAMEWORK}

The Briggs model begins with a cycle of aspiration, imagining and developing expectations. According to Briggs, during this stage, the student imagines and aspires to be a university student who is developing relevant education-related skills and knowledge. "This leads to commitment to apply and take up a university place." [1] This study has provided an exploration of the experience of associate students pre- and post-transition. This framework is born out of the recognition that associate student have a different experience, they develop their commitment earlier, and the interventions provided inform their aspiration and expectations. The dual enrolment afforded to them as associate students inform their transition experience, their commitment and the timing and impact of their adjustment. The area of contribution from this study does not cover the entire Briggs model but instead focuses on the pre-transition stage at college and the extended adjustment stage during the first trimester at university.

\section{A. Aspiring}

This study has shown that, in agreement with [1]) raising aspiration is important. Aspiration can be defined as hope or ambition of achieving something. The participants were hopeful for their career aspirations and recognized the importance of a degree in helping them achieve their goals. They were motivated and inspired for their future - 'It's amazing here. It makes me wonder where my future will lead' (P22).

The associate students in this study had raised their aspirations and were 'ready to move on and for the challenge. I don't feel like a college student anymore, being at Merchiston definitely made a difference, it, like, changed my whole mindset' (P14). Being allowed to experience the university environment, over an extended period clearly increases aspiration and is an important contributor to the positive experience of the associate students. These feelings are linked very closely with their student identity and how they imagine university study to be.

\section{B. Imagining}

Some of the participants described feeling like a 'real' student when they visited the campus and described it as ' $a$ much more grown-up environment' (P16). They didn't need to imagine, they could experience, and they were university students. Imagining themselves as graduates had a profound impact on some - 'I hope to see myself in one of those gowns. It's a reality check' (P27).

Throughout this study, the participants demonstrated that their self-image and future aspirations were not fixed. Some experiences motivated and confirmed their confidence in university studies, others overwhelmed and made them question their ability. Allowing these experiences and the consequent impacts to occur early in their college studies, provides space for development and personal growth.

\section{Developing expectations}

The associate students develop expectations, and the interventions allow them to experience university life, to meet staff and students and experience the campus.
Developing expectations is closely related to preparation activities. This study has demonstrated that experiencing university life and preparation activities ensures students have a clear path into the third year of the degree program. For some, the development of this awareness caused levels of anxiety with one participant commenting on a lecture theatre as being 'really intimidating' (P24).

This study agrees with [1] that learners expect that they will learn more independently at university, with participants confirming that 'the majority of the stuff is your own work' (P25).

\section{Awareness of skills and knowledge}

During community college, students were also said to be acquiring skills and knowledge, 'they develop pre-transition the skills and knowledge that support independent undergraduate learning' [1]. However, the proposed model deviates from this; the students in this study were found to have an awareness of the skills needed for successful university study but they were less active in acquiring these. For this reason, this was replaced with 'Awareness of Skills and Knowledge'.

This was confirmed by $\mathrm{P} 12$ who stated '[university lecturers] must know we just join from college and are unprepared' (P12). The participants were aware of academic differences, of differences in programming languages, software specifications and much more. However, there was little evidence that most students acted upon this information. After transition, however, they reflected that both the college and university should have covered these items in more detail - some of the skills I feel, like referencing and reports, they should have taught us that at college. It should have been covered in more detail here' (P27).

\section{E. Adjustment}

In her research, Briggs then showed the student journey as progressing to adjustment. Students in this study were found to experience a vital and extended period of adjustment. This research has identified five fundamental influences on an associate student transition, and these emerged throughout the study as superordinate themes.

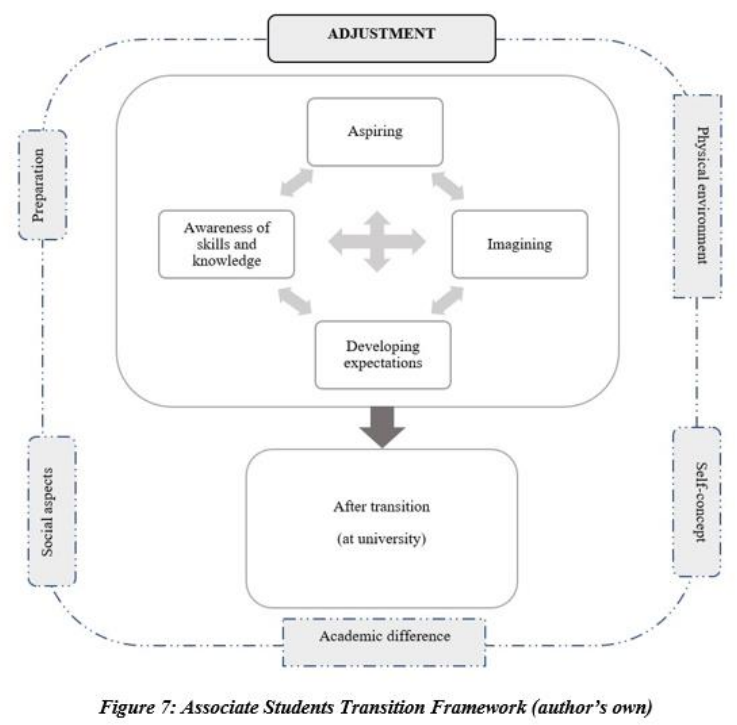


Adjustment is not a step in a process, it is a period of time which varies for each individual. For the associate students in this study, adjustment begins during the interventions whilst they study at college before and continues way beyond their transition. In the new framework, adjustment becomes a grey area, represented by a broken line, which envelops all stages - from college into their first trimester and beyond.

The framework identifies five new areas (discussed below) with each one being informed by the findings of this study and grounded in the literature. Understanding the experience of students in transition has identified these components along with key themes and areas highlighted by the literature.

\section{1) Preparation}

This research found that associate students at college felt the role of preparing them for the transition to university lay with the college, with several stating that 'college hasn't really prepared us' $(\mathrm{P} 13)$ and 'I think within the college there could have been more about planning how to do things and how to look ahead' (P5). Although existing research explored the impact of adjustment and [38] stress the importance of allowing applicants to imagine what being a university student is like before and during transition, the research failed to explore what preparedness means from an individual perspective.

Associate students shared awareness of academic skills such as report writing and referencing - 'some of the skills I feel, like referencing and reports, they should have taught us that at college. I know that every report at uni you need to do that. It should have been covered in more detail here' (P27). Despite their awareness of the skills gap, very few of the associate students took personal responsibility for resolving this. Some looked to the university for adjustments - 'They [university lecturers] must know we just join from college and are unprepared' (P12). A few of the participants were prepared, stating 'It still took a bit of adjustment but being an associate student and having had that level of involvement meant I had the confidence to take that on' (P11).

This study confirms that for students in transition from community college to university, despite numerous interventions and opportunities to explore and experience the university, preparation takes place before, during and after transition.

\section{2) Self-concept}

The participants in this study had the opportunity to identify as a college student, a university student or an associate student. Some identified as more than one and this varied depending on circumstance and self-esteem. For some, being an associate student allowed them to progress to university - a journey they hadn't anticipated. For others, imagining themselves as a university student increased their motivation and encouraged them to alter their behavior to increase their chances of success - '....I have a lot more focus and am a lot more motivated. I'm motivated to be a university student, much more than I ever was in college' (P22). Coming from college was seen as a 'different world' (P2) by others, and their experience during adjustment made them feel like a 'new student' (P2).
How the participants identified was not found to be significant. The significance and impact of the associate student project lies in the opportunity for progression. To feel worthy and accepted, to realize you have a place. Students adapted to their new self-concept and many thrived in the higher expectations, and the onus placed upon them to adapt and exhibit their university status [46][47]. Some struggled in the unfamiliar environment and more can be done to ensure staff work to enforce positive dialogues and expectations from associate students.

\section{3) Social aspects}

The framework includes social aspects as fundamental to adjustment. This study showed that associate students who move to university with existing classmates benefited from the comfort this brought - 'we know most of the people in the class so it's not going to be as intimidating' (P23). Although class size has been highlighted as an academic difference, participants highlighted the significance of the social aspects - 'there's a different kind of relationship. You're not as close to your lecturers here' (P24). Students also experienced feelings of loss - 'there is not this sense of unity, kind of. Like, a class or group that you had in college' (P12). Several of the participants discussed feelings of loneliness and isolation and highlighted the significance of their existing friendship group and sticking with the people they knew.

Social adjustment takes place as students adjust to their new circumstance. Sticking with existing groups during adjustment allows the students to confirm current expectations and beliefs [39]. This safety net can increase confidence and encourage identification with the university [40].

Only one of the participants had joined a university society and research has shown that this is beneficial for social integration. Universities must acknowledge the changing demographic of their student body where directentrants and those defined as 'new students' [41]individuals who only attend timetabled sessions [42] are spending vastly shorter periods of time on campus [43] than traditional higher education students.

\section{4) Physical environment}

The study agrees with previous authors that the change in physical location and finding your way around a new campus is 'a bit scary' (P13) and requires adjustment over time. Having access to the campus during their college studies provided opportunities for aspiration raising and familiarization. However, despite previous campus tours and visits to lecture and tutorial rooms, participants got lost and experienced anxiety.

Associate students were inspired by the campus before transition and after transition were complimentary of the enhanced resources and facilities such as library, study spaces and 24-hour access. Outside the campus, a small proportion of the participants had moved to new living accommodation and were experiencing adjustment to a new city and environment. These are significant life changes but none of the academics in the study acknowledged the outside influencers which students were dealing with.

5) Academic differences 
It is very important to increase awareness and understanding of the academic differences experienced by associate students. The literature has told us that institutions should build links and continuity [44], highlighting the significance of adjustment to the new academic and social demands [45]. This academic difference is not preparedness, it is understanding, awareness and acceptance of the specific changes in pedagogy and assessment. Research around the specific changes focused on self-direct learning and preparedness [42][43].

Within this study, academic difference was the only theme identified by all participants. The participants realized 'it's going to be tough' (P13) and 'I don't think the way we write, and work is the same, there are different levels' (P13). They realized that self-directed study was important - 'it's up to you if you look at it, if you want to progress your own learning' (P29).

These findings have demonstrated that students, pre- and post-transition, are aware of the difference in skills and knowledge between the educational establishments. What is surprising is that there is little effort, at least from the discussion in this study, of either the students themselves trying to update their skills accordingly, or of academics adjusting the content of their teaching to ease or allow for adjustment post-transition.

\section{CONTRIBUTION AND FUTURE WORK}

This paper adds to the existing body of knowledge on transition by filling a gap in the understanding of the perceptions and experiences of associate students. This is an important area which is under-researched. In addition, developing a framework of associate student transition has created a method for disseminating the findings to the wider HE community. This framework builds on existing work and allows for community college and university staff to develop their own methods of support focusing on this key group of students and their specific needs through the stages of transition.

The issues and topics explored in this paper provide an opportunity for future research. The framework suggested in this study is not definitive but provides insight into the individual participants in this study and represents their perceptions and experience of transition. The framework produced should be applied in alternative transition situations such as primary to secondary school and non-standard routes to understand appropriate support methods and to add to the body of work around student transition.

During the final academic year of this study, 2020/21 COVID-19 dominated the world. This caused learning and support services within universities and colleges to move online. There will be long term consequences across education at all levels. Future research to examine the impact on students, particularly those in transition, would allow student support to be tailored appropriately and would add to an important area of research.

This study has been primarily concerned with the perceptions and experience of associate students. The nature of this data does not allow the researcher to determine what a true account is, nor does it allow for generalizations to be drawn. One of the main limitations of the study was the small number of participants and the tight window of data collection. Although IPA requires a small number of participants, this, aligned with data collection for each group at one point in time, has only provided a narrow view of the students' transition.

However, this project is the first comprehensive investigation of associate students using both graphical research and IPA methods. The insights gained from this study may be of assistance to further and higher education institutions and are a valuable addition to the work on transition.

\section{REFERENCES}

[1] A. R.J. Briggs, J. Clark, and I. Hall, "Building bridges: understanding student transition to university". Quality in Higher Education, vol. 18(1), pp. 3-21, 2012.

[2] K. Gravett, I.M. Kinchin, and N.E. Winstone, "Frailty in transition? Troubling the norms, boundaries and limitations of transition theory and practice". Higher Education Research \& Development, vol. 39(6), pp. 1169-1185, 2020.

[3] Commission on Widening Access. "A Blueprint for Fairness: The Final Report of the Commission on Widening Access". 2016.

[4] J. Coughlan, and S. Swift, "Student and tutor perceptions of learning and teaching on a firstyear study skills module in a university computing department". Educational Studies, 2011.

[5] J. Lindstrom, "Review of The saturated self: Dilemmas of identity in contemporary life". Journal of Theoretical and Philsophical Psychology, vol. 13, pp. 160-166, 1993.

[6] A. Brown, A. Dennis, L. Gordon, S. Howden, and D. Jindal-Snape. "Evaluation of Year 3, and the full three-years of the Student Transitions Enhancement Theme Evaluation Report, 2017.

[7] D. Jindal-snape, "Reconceptualising Transitions : Whose Transition is it Anyway?" In Enhancement and Innovation in Higher Education, pp. 1-5, 2015.

[8] S. Kift, "Articulating a transition pedagogy to scaffold and to enhance the first year student learning experience in Australian higher education”. Final Report for ALTC Senior Fellowship Program, 2009.

[9] S. Towns, "Measuring up: an examination of the expectations and realities of students during the primary to secondary transition". S. C. University, Ed., 2011.

[10] L. Allen, and J. Storan, "Widening Participation: A Rough Guide for Higher Education Providers", 2015.

[11] D. Horsburgh, "University Outcome Agreements", 2018.

[12] C. MacRitchie, and K. Adesokan, "SFC Triennial Review on Widening Access, 2017.

[13] L. Tett, V. E. Cree, and H. Christie, "From further to higher education: transition as an on-going process", vol. 73, pp. 389-406, 2017.

[14] M. Palmer, P. O'Kane, and M. Owens, "Betwixt spaces: Student accounts of turning point experiences in the first-year transition". Studies in Higher Education, 2009.

[15] S. Penn-Edwards, and S. Donnison, S., "Engaging with higher education academic support: A first year student teacher transition model". European Journal of Education, 2011.

[16] H. Christie, "Emotional journeys: young people and transitions to university". British Journal of Sociology of Education, vol. 30(2), pp. 123-136, 2009.

[17] C. Leathwood, and P. O'Connell, P., "It's a struggle": The construction of the "new student" in higher education". Journal of Education Policy, 2003.

[18] J. E. Rhodes, R. Spencer, T. E., Keller, B. Liang, G., Noam, A. L., Zevallos, and M. Washburn, "Creating a Culture of Student Success: The SEEK Scholars Peer Mentoring Program”, 2014. 
[19] L. Thomas, "I use my time more wisely..." The implications for learning and teaching in higher education of more "commuter students", 2018.

[20] E. Young, R. Thompson, J. Sharp, and D. Bosmans, "Emotional transitions? Exploring the student experience of entering higher education in a widening-participation HE-in-FE setting”. Journal of Further and Higher Education, 2019.

[21] J. Waters, and K. Gibson, "Lost at the Starting Gate: An Investigation into the Psycho-social Causes of Withdrawal from Access Courses". Widening Participation and Lifelong Learning, 2001.

[22] L. Aynsley, and S. Gazeley, "The contribution of pre-entry interventions to student retention and success. A literature synthesis of the Widening Access Student Retention and Success National Programmes Archive". Higher Education Academy, 2012.

[23] A. M. Huberman, and M.B. Miles, "Data Management and Analysis Methods". Handbook of Qualitative Research, 1994.

[24] J. W. Creswell, "Qualitative inquiry and research design: Choosing among five traditions". Qualitative Health Research, 1998.

[25] J. W. Creswell, "Research Design: Qualitative, Quantitative and Mixed Methods Approaches (4th ed.), 2014.

[26] D. Harper, "Talking about pictures: a case for photo elicitation". Visual Studies, vol. 17(1), 2002.

[27] M.E. Thomas, “Auto-Photography”. In International Encyclopedia of Human Geograph, 2009.

[28] K. G. Heider, J. Collier, and M. Collier, "Visual Anthropology: Photography as a Research Method". The Journal of American Folklore, 1988.

[29] N. King, and C. Horrocks, "Carrying Out Qualitative Interviews". Interviews in Qualitative Research, 2010.

[30] P. Papaloukas, K. Quincey, and I. R. Williamson, "Venturing into the visual voice: combining photos and interviews in phenomenological inquiry around marginalisation and chronic illness". Qualitative Research in Psychology, vol. 14(4), pp. 415-441, 2017.

[31] A. Radley, and D. Taylor, "Images of recovery: A photo-elicitation study on the hospital ward". Qualitative Health Research, 2003.

[32] C. Wang, M. Burris, and X.Y. Ping, "Chinese village women as visual anthropologists: A participatory approach to reaching policymakers". Social Science and Medicine, 1996.

[33] K. Hernandez, A.N. Shabazian, and C. McGrath, "Photovoice as a Pedagogical Tool: Examining the Parallel Learning Processes of College Students and Preschool Children through Service Learning”. Creative Education, 2014.

[34] M. Keeffe, amd D. Andrews, "Towards an adolescent friendly methodology: accessing the authentic through collective reflection". International Journal of Research and Method in Education, 2015.
[35] L.T. Madden, and A.D. Smith, "Using Photographs to Integrate Liberal Arts Learning in Business Education". Journal of Management Education, 2015.

[36] J. Moss, and B. Pini, "Visual research methods in educational research". Visual Research Methods in Educational Research, 2016.

[37] J.A. Smith, "Reflecting on the development of interpretative phenomenological analysis and its contribution to qualitative research in psychology". Qualitative Research in Psychology, 2004.

[38] A. R.J. Briggs, J. Clark, and I. Hall, "Building bridges: understanding student transition to university". Quality in Higher Education, vol. 18(1), pp. 3-21, 2012.

[39] J. Lindstrom, "Review of The saturated self: Dilemmas of identity in contemporary life". Journal of Theoretical and Philsophical Psychology, vol. 13, pp. 160-166, 1993.

[40] A. Lizzio, "Designing an orientation and transition strategy for commencing students". A Conceptual Summary of Research, 2006.

[41] T. Haggis, "Pedagogies for diversity: retaining critical challenge amidst fears of "dumbing down." Studies in Higher Education, vol. 31(5), pp. 521-535, 2006.

[42] H. Christie, "Day Students" in Higher Education: widening access students and successful transitions to university life. International Studies in Sociology of Education, vol. 15(1), 2005.

[43] M. Yorke, and B. Longden, "Retention and student success in higher education". Society for Research into Higher Education \& Open University Press, 2004.

[44] F. Rice, N. Frederickson, K. Shelton, L. Riglin, and T. Ng-knight, "Identifying factors that predict successful and difficult transitions to secondary school”, pp. 1-47, 2015.

[45] B. Rickinson, and D. Rutherford, "Systematic monitoring of the adjustment to university of undergraduates: A strategy for reducing withdrawal rates". British Journal of Guidance and Counselling, 1996.

[46] L. Harvey, S. Drew, and M. Smith, "The first-year experience: a review of literature for the Higher Education Academy". The Higher Education Academy, 2006.

[47] M. Yorke, and L. Thomas, "Improving the Retention of Students from Lower Socio-economic Groups". Journal of Higher Education Policy and Management, 2003.

[48] 